\title{
SPONTANEOUS RUPTURE OF A NORMAL SPLEEN IN A HAEMOPHILIAC
}

\author{
*J. ANDERSON, M.B., B.S., M.R.C.P. \\ Lecturer in Medicine
}

I. V. LISHMaN, M.B., Ch.B., F.R.C.S., F.R.C.S. (Ed.)

†T. J. MUCKLE, M.B., B.S. Senior Surgical Registrar

\author{
Lecturer in Pathology
}

Department of Medicine and Pathology,

University of Newcastle upon Tyne.

and

Royal Victoria Infirmary, Newcastle upon Tyne.

SURGERY in haemophilia has a serious reputation and the average surgeon will have only occasional experience in this condition. His judgement, especially in emergency surgery, may be affected by previous reports of a high mortality, all the more so if he must operate in the absence of supplies of anti-haemophilic factor (AHF).

We wish to record the successful outcome of a case of spontaneous rupture of a normal spleen treated by emergency splenectomy without the benefit of AHF cover.

\section{Case Report}

The patient, J.H., aged 23 years, is a known haemophiliac with no family history of any bleeding disorder. The condition had been noted first at the age of two years, when a laceration of the tongue bled profusely and hospital admission for blood transfusion was necessary. Frequent hospital admissions followed, including one for an episode of haematuria at the age of 11. In 1956, at the age of 15 , the diagnosis was confirmed when a thromboplastin generation test showed deficiency of antihaemophilic factor (AHF). Further hospital admissions for dental extractions and various haemarthroses followed. On every occasion, haemorrhage ceased rapidly after transfusion of fresh frozen plasma (FFP).

On the 28th December, 1962 at 1.00 p.m., the patient was admitted under the care of Professor G. A. Smart. Two days previously he had developed mild epigastric pain associated with nausea and vomiting. No history of injury of even a minor type could be obtained from our patient or his relatives. These symptoms persisted, and 24 hours before admission he suddenly developed a severe pain under the lefit costal margin which radiated to the left shoulder. This pain continued and in the next eighteen hours his mother noticed that he was becoming rapidly paler.

On admission his condition was grave. He was ashen grey, sweating and was in peripheral circulatory failure. The radial pulse was not palpable and the blood pressure was not recordable. The heant rate was 140 per minute. There were resolving haemarthroses affecting both knees. The abdomen was distended and did not move on respiration. On palpation he was acutely tender with muscle guard-

*Present Address: Dept. of Internal Medicine, University of Virginia Hospital, Charlottesville, Va. $\dagger$ Address for Reprints:-Dr. T. J. Muckle, Royal Victoria Infirmary, Newcastle upon Tyne. ing and rigidity maximal in the left hypochondrium. There was dullness to percussion in both flanks and in the left hypochondrium, while bowel sounds were absent. Rectal examination was normal and the faeces were negative for occult blood. Examination showed no external evidence of bruising or abrasions while radiology excluded fracture of the ribs. A diagnosis was made of intra-peritoneal haemorrhage, and the possibility of spontaneous rupture of the spleen was considered. At this time it was agreed that laparotomy would be necessary but that the patient's shock and level of AHF should be corrected as far as possible before embarking on surgery.

Management: An intravenous drip was erected and the patient was given $500 \mathrm{ml}$. of reconstituted dried plasma followed by $1500 \mathrm{ml}$. of stored old blood, while fresh blood and fresh frozen plasmog were being obtained. We considered the possibility of obtaining human anti-haemophilic Factor (AHF) from the nearest source of supply at Edinburgh, but the weather conditions at the time prevented this, either by road or air, and considerable delay would have been inevitable. The first 21 . of intravenous fluid were given in two hours, and by this time the radial pulse was palpable at 120 /minute and the blood pressure was $100 / 60 \mathrm{~mm} \mathrm{Hg}$. Over the next six hours, he was given a further 21 . of fresh blood and $1 \mathrm{l}$. of fresh frozen plasma and this was accompanied by some improvement in his general condition. By 9.00 p.m. his clotting time was three minutes. Unfortunately no facilities were available at this time or later for AHF assays, and on the day of admission of a thromboplastin generation test could not be performed at the short notice given. However, some nine hours after admission his condition began to deteriorate. A further 11 . of fresh blood was given in the next hour, and it was decided not to postpone laparotomy further. At midnight therefore, 11 hours after admission, laparotomy was performed by Mr. P. H. Dickinson, with Dr. E. I. Tate as anaesthetist.

Operation: A middle epigastric incision was made. The peritoneal cavity was full of blood, both fluid and clotted, some 31 . being removed. There was a huge subcapsular splenic haematoma which had burst leaving a ragged spleen. A hand was passed over the lateral surface of the spleen and no adhesions were encountered between it and the diaphragm. The spleen was lifted forward and the posterior layer of the lieno-renal ligament was rapidly divided to allow delivery of the organ through the wound as quickly as possible. During this procedure the spleen distintegrated and the vessels in its pedicle were controlled manually before ligation. 
A stab drain was inserted and the wound closed in layers. There was no unusual bleeding either from the wound or from the splenic pedicle.

In the period immediately before, during, and after the operation, a further 31 . of fresh blood were given-a final total of 61 . of fresh blood, 1.51 . of stored blood and $1.5 \mathrm{l}$. of dried or frozen plasma having been given over 13 hours. On return from theatre, the patient's immediate post-operative condition was satisfactory.

Progress: With improvement in weather conditions the following morning we were able to obtain, by the kind co-operation of Dr. H. Davies at Edinburgh Royal Infirmary, a supply of human AHF. (One unit of $200 \mathrm{ml}$ is prepared from $1350 \mathrm{ml}$ of FFP). The following regime of intravenous therapy was used for three weeks :-

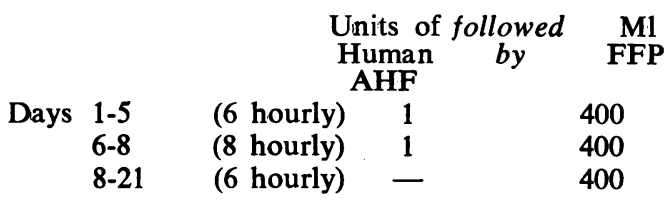

Three weeks after operation intravenous therapy was discontinued. By this time the wound had healed completely. There were no haemorrhagic complications post-operatively and no further blood transfusion was necessary. Progress, as regards his haemophilia, was unexpectedly smooth.

Histological examination of the spleen was normal. Subsequent Paul-Bunnell serology and white cell counts excluded infectious mononucleosis.

Two post-operative complications did arise, however. Eighteen hours after operation acute left ventricular failure developed. It was presumed to be due to over-transfusion, and it responded well to venesection of $500 \mathrm{ml}$. of blood. There was no recurrence. Some three weeks after operation he developed a haemarthrosis of the lefit knee which became spontaneously infected with staphylococcus aureus. Appropriate antibiotics were given and the condition improved in time, although some permanent damage persists in the knee, which had been the site of previous haemarthroses.

A later setback was the development of haematuria, which did not cease with further transfusion of fresh frozen plasma. Because of difficulties regarding supplies of AHF, he was transferred to the Churchill Hospital, Oxford, under the care of Dr. Rosemary Biggs. The haematuria remained troublesome but eventually settled after intensive therapy. By this time he had made a complete recovery from his splenectomy, and this last episode is simply mentioned to complete the picture.

The patient was eventually discharged home and since then has remained well with no haemorrhagic episodes. The movement of his left knee is limited but causes little trouble and he has returned to work as a clerk.

\section{Discussion}

\section{Bleeding in Haemophilia}

Haemophilia $\mathbf{A}$ is an allelic genetic trait transmitted from mother to male offspring although it does occur very rarely in females. Affected patients fail to produce adequate AHF. Blood clotting is impaired and severe bleeding may therefore occur from even minimal trauma.

Haemarthroses, soft tissue haematomata, and bleeding into the gastrointestinal tract or urinary tract are the more common manifestations of haemophilia. Intraabdominal bleeding may be found especially in the retroperitoneum, in the substance of the ilia-psoas muscle or in the anterior abdominal wall muscles. Intraperitoneal bleeding is rare, Kerr (1963) only recording two examples from his large series. One resulted from a brawl while the other followed a bout of severe coughing.

\section{Rupture of the Spleen}

Rupture of the spleen is a well-known intraabdominal catastrophe, and is usually associated with trauma. Spontaneous rupture is said to occur when the patient denies any history of injury. The definition cannot be exact because minimal trauma may be forgotten, or trauma denied if domestic quarrels are involved.

The diseased spleen is more prone to rupture than normal, and spontaneous rupture has been described in a number of conditions. Among recently reported examples may be mentioned infectious mononucleosis (York, 1962; Freeman 1962), malaria (Bearn, 1961), and leukaemia (Wolfson, Croce and Fite, 1954; Flood and Car-8 penter, 1961). Rupture of the diseased spleen has also been reported in association with sarcoidosisc multiple myeloma, Gaucher's disease, bilharziasis and typhoid, as well as in acute febrile illnesses. Spontaneous rupture of an apparently normal spleen has been recorded on a number of occasions (Ferrand, d'Eshougues, Robert, Barsotti and Streit, 1959; Perl, Darter and Milles 1958; Orloff and Peskin, 1958; Morrin and Buiney, 1961; Graham, 1960; and Smith, Rodriguez, Meade, 1962), and the condition has been reviewed by Brodman and Bautista, 1959; Comacho, 1959; and Husni and Turell, 1961. The catastrophe has also been described in association with pregnancy (Embrey and Painter, 1962).

Spontaneous rupture of the spleen has not been recorded previously in haemophilia, although traumatic rupture has occurred (Pitney, 1959; van Creveld, Koppe, Mochtar and Mulder, 1962). Splenectomy was performed as a trial method in the treatment of haemophilia (Gross, Hartman and Graham, 1957) but was abandoned because of the disastrous results.

\section{Surgery in Haemophilia}

Surgical intervention in haemophilia has a serious reputation, and reports of a high mortality have long been a deterrent to elective and emergency surgery. In 1948 there were only ten reported cases in the literature of surgery in haemophilia, and appendicectomy was held to have a $50 \%$ mortality (Craddock, Fenninger and Simmons, 1948).

By 1959 , some fifty cases were reported having 
undergone major surgery (Pieper, Perry and Burrough, 1958) and in 1960 sixteen cases of intra-abdominal surgery were collected (Passaro, 1960). In this group it was found that surgical mortality was not significantly different from that in non-haemophiliacs undergoing similar surgery, although a higher morbidity was found. In our own hospital an elective partial gastrectomy was performed successfully on a known haemophiliac (Lowdon, 1960).

Recent reports by Italian (Marini, 1961), Hungarian (Feszler and Borgsonyi, 1960), German (Herzog, 1960) and Russian (den Mukhamadov and Orlov, 1960) authors show that surgery is attempted more often with a safer outcome if there is careful attention to pre- and postoperative management. Kerr (1963) records a similar experience in the management of 132 haemophiliacs at the Royal Prince Alfred Hospital, Sydney, Australia, in the period 1942-1961. Methods of Raising the AHF Level

AHF is involved in the second phase of haemostasis. This begins a few minutes after the initial tissue damage when the formation of a strong and stable blood clot consolidates the primary platelet phase. Its importance diminishes five to seven days later, when the clot has provided a firm basis for the beginning of the third phase, fibrous organisation.

The only satisfactory method of securing this second phase in haemophilia $A$ is transfusion of some form of AHF, and three basic considerations guide such therapy:-

(i) AHF levels approaching the lower limit of normal $(50 \%)$ are essential to formation of the normal blood clots required for protracted haemostasis. Ideally then, severe haemophiliacs should receive sufficient AHF to maintain their plasma levels well within the normal range from the commencement of surgery until 5-7 days thereafter. Because of haemodynamic limitations of the volume of transfusions, and the fact that the half-life of transfused AHF may be as short as seven hours (Biggs and Denson, 1963), this result can often only be achieved with certainty by giving a concentrated human or animal preparation every five or six hours.

(ii) However, once clot organisation has begun, haemostasis can usually be maintained by the use of fresh frozen plasma alone to raise the patient's circulating plasma AHF levels to the region of $35 \%$ for a period of two hours every eight to twelve hours. Allowing a plasma volume of 2,500 $\mathrm{ml}$. this may be attained bv transfusion of 1,500 to $2,000 \mathrm{ml}$. daily until healing is complete about the fourteenth day. Since clots formed at AHF levels below $30 \%$ have little haemostatic value, clearly the levels must be "peaked" by giving the plasma as rapidly as possible on each occasion, short of haemodynamic embarrassment.

(iii) Individual haemophiliacs vary in their plasma response to the administration of known amounts of AHF. Further, the AHF content of

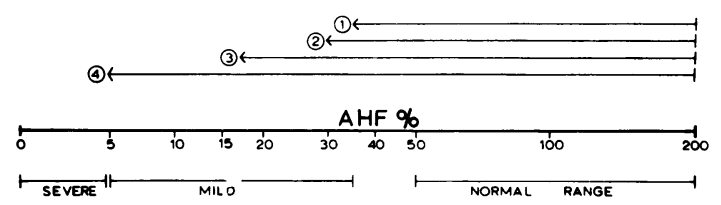

FIG. 1.-Chart showing plasma AHF levels below which some routine coagulation tests are usually abnormal.

1. Thromboplastin Generation Test.

2. Re-calcified Plasma Coagulation Time.

3. Prothrombin Consumption Test.

4. Whole Blood Clotting Time.

fresh frozen plasma is, by the time of giving usually an uncertain quantity. Precise control of therapy therefore necessitates knowledge of the immediate post-transfusion AHF level in the patient's plasma, and the rate at which it declines thereafter. Specific AHF assay is essential to such precision, and a variety of techniques are in current use (Biggs and Macfarlane, 1962; Hardisty and Macpherson, 1962; Pitney, 1956; Pool and Robinson, 1959; Wolf, 1959). For less exact control it may be sufficient to know that the circulating AHF concentration is above $30 \%$, when a simple thromboplastin generation tese (Biggs and Macfarlane, 1962) will provide the information. It is obvious from Figure 1 that other mundane routine coagulation tests are of little or no value in this respect since they mase appear normal in the presence of marked AHF deficiency. Furthermore, their results may vary throughout their range with concentration differences of many of the other coagulation factors.

\section{Post-operative Complications}

In Passaro's series the commonest complication was post-operative bleeding from the wound or the site of gastro-intestinal anastomoses. The second commonest group of complications were associated with transfusion itself. Sensitivity reactions may occur, and limit the use of animal antihaemophilic factors. For this reason human AHF is preferred but allergy may still be a problem. This danger may be reduced by regular doses of antihistamine or cortisone during the period of transfusion. Our patient received antihistamines and no allergic manifestations developed.

A relatively large volume of fluid may have to be transfused in order to raise and maintain the AHF level and to combat shock. There is thus a considerable danger of overloading the circulation, and this occurred in our patient but was promptly relieved by venesection. In an older patient with an abnormal cardio-vascular system the danger would be greater. It is recommended therefore that careful watch should be kept for early signs of congestive cardiac failure. 


\section{Conclusion}

This case demonstrates that emergency major surgery need not be denied to a haemophiliac in the absence of anti-haemophilic factor if fresh frozen plasma and fresh blood are available.

\section{Summary}

A case is described of a haemophiliac with spontaneous rupture of the spleen who was successfully treated by splenectomy under cover of fresh frozen plasma and fresh blood.

The post-operative period was covered by transfusion of human anti-haemophilic factor and fresh frozen plasma. The literature relating to spontaneout rupture of the spleen is briefly reviewed, and the present position with regard to surgery in haemophilia is discussed.

We would like to thank Professor G. A. Smart and Mr. P. H. Dickinson for permission to report this case. We are particularly grateful to Dr. H. Davies of Edinburgh Royal Infirmary for his advice and for supplies of human AHF, and to Dr. S. Murray of the Newcastle Regional Blood Transfusion Service for supplies of FFP. We are also grateful to Dr. Rosemary Biggs of Oxford for taking over the patient and for treating his persistent haematuria successfully.

\section{REFERENCES}

BEARN, J. G. (1961): Spontaneous Rupture of the Malarial Spleen, Trans. roy. Soc. trop. Med. Hyg., 55, 242.

Biggs, R., and Denson, K. W. E. (1963): The Fate of Prothrombin and Faotors VIII, IX and X Transfused to Patients Deficient in These Factors, Brit. J. Haemat., 9, 532.

BigGS, R., and MacFarlane, R. G. (1962): Human Blood Coagulation and its Disorders. 3rd Ed., Oxford: Blackwells.

Brodman, H. R., and Bautista, J. (1959): Spontaneous Rupture of the Normal Spleen, Arch. Surg., 78, 406.

CamaCHO, E. (1959): Splenic Rupture: with Consideration of the So-called Spontaneous Rupture of the Spleen, Henry Ford Hosp. Bull., 7, 30.

Craddok, C. G., Fenninger, L. D., and Simmons, B. (1948): Haemophilia, Ann. Surg., 128, 888.

Creveld, S. Van, Koppe, M. J. G., Mochtar, I. A., and MULDER, E. (1962): Extirpation of the Spleen Because of Traumatic Rupture in Haemophilia A, Maandschr. Kindergeneesk, 30, 351.

Den Mukhamedov, S. R., and ORLOV, A. S. (1960): Haemophilia in Urological Practice, Urologiya, 25, 30.

Embrey, M. P., and Painter, N. S. (1962): Haemoperitoneum due to Spontaneous Rupture of the Spleen in Pregnancy, Brit. J. Surg., 49, 575.

FERRAND, J., D'EShOUGUeS, J. ROBERT, BarsotTI, J., and STREIT, R. (1959): Spontaneous Rupture of an Apparently Normal Spleen, Mém. Acad. Chir., 85, 188.
Feszler, G., and Borzsonyl, L. (1960): On the Operability of Haemophiliacs, Magy. Sebész., 13, 242.

Flood, M. J. and Carpenter, R. A. (1961): Spontaneous Rupture of the Spleen in Acute Myeloid Leukaemia, Brit. med J., i, 35.

Freeman, A. R. (1962): Rupture of the Spleen in Infectious Mononucleosis, Brit. med J., ii, 96.

GraHAM, J. W. (1960): Spontaneous Rupture of the Normal Spleen, Med. J. Aust., i, 295.

Gross, J. D., hartman, R. C., and Graham, J. B. (1957): Splenectomy in Haemophilia, Johns Hopk. Hosp. Bull., 100, 223.

Hardisty, R. M., and MacPherson, J. C. (1962): A One Stage Factor V.III (Antihaemophilic Globulin) Assay, and Its Use on Venous and Capillary Plasma, Thrombos. Diathes. haemorrh. (Stuttg.), 7, 215.

Herzog, C. H. (1960): Surgical Experience in Haemophilia, Münch. med Wschr., 102, 2396.

HuSNI, E. A. and TURell, D. (1961): Spontaneous Rupture of the Normal Spleen, Arch. Surg., 83, 286.

KERR, C. B. (1963): The Management of Haemophilia. Sydney: Australasian Medical Publishing Company.

LowDON, A. G. R. (1960): Personal Communication.

Marini, M. P. (1961): Personal Experience in the Preparation of Haemophilic Patients for Surgical Intervention, Minerva anest., 27, 117.

Morrin, F. J., and GuINEY, E. (1961): Spontaneous Rupture of the Normal Spleen, Irish J. med Sci., Sixth Series, No. 43, 500 .

Orloff, M. J., and Peskin, G. W. (1958): Spontaneous Rupture of the Normal Spleen-a Surgicalc Enigma, Int. Abstr. Surg., 106, 1.

Passaro, E. P. Junior, DetTman, P. M., and SMith, B. (1960): Surgery in the Haemophiliac Patient, Arch. Surg., 81, 864.

Perl, JohN I., DarTer, Robert W., and Milles, GEORGE (1958): Spontaneous Rupture of a Normal Spleen: and Report of a Case, J. int. Coll. Surg., 30, 420 .

PiePer, G. R., Perry, S., and Burrough, J. (1959): Surgical Intervention in Haemophilia, J. Amer. med. Ass., 170, 33.

Pitney, W. R. (1956): The Assay of Antihaemophilic Globulin (A.H.G.) in Plasma, Brit. J. Haemat., 2, 250.

Pitney, W. R. (1959): The Management of the Patient with a Haemostatic defect during Surgery, Med. J. Aust., 46(i), 65.

Pool, J. G., and RoBINSON, J. (1959): Assay of Plasma Antihaemophilic Globulin (A.H.G.), Brit. J. Haemat., 5, 17.

Smith, O. F., Rodriguez, M., and Meade, J. W. (1962): Spontaneous Rupture of the Normal Spleen, A Case Report, R.I. med. J., 45, 255.

WOLF, P. (1959): Preparation and Clinical Use of a Concentrate of Human A.H.F. p. 48. M.D. Thesis, University of Manchester.

Wolfson, I. N., CROCE, E. J., and Fite, F. K. (1954): Acute Leukaemia with Rupture of the Spleen as the Initial Symptom, New Engl. J. Med., 251, 735 .

YORK, W. H. (1962): Spontaneous Rupture of the Spleen-Report of a Case Secondary to Infectious Mononucleosis, J. Amer. med Ass., 179, 170. 